\title{
CORRESPONDENCE
}

\section{Eleven peak flow meters: a clinical evaluation}

\section{To the Editor:}

The introduction of several new types of inexpensive hand-held peak flow meters has given rise to much confusion and this has been compounded by the existence of two entirely different scales in which peak expiratory flow (PEF) may be measured. The intention of the study by Folgering et al. [1], reported in the January issue of the Journal, was to resolve this confusion by evaluating the accuracy, reproducibility and linearity of seven standard range and four low range hand-held meters. It is regrettable, therefore, that a study with such commendable aims was so seriously flawed that its findings and conclusions, so far from reducing present confusion, will have served only to increase it.

Surprisingly, the authors did not refer to a previous study [2] that they presented at the 1993 meeting of the European Respiratory Society, whose methods, findings and conclusions were virtually identical to those of their recent study. In conversation and correspondence with one of the authors, I drew attention to the fact that whereas most of the meters they had studied were calibrated on the "ATS" scale adopted by the American Thoracic Society (ATS), some were calibrated on the "Wright" scale introduced in 1959 by WRIGHT and McKeRROw [3] and regar-ded until a few years ago as the universal standard of PEF calibration. Since there are substantial differences between the two scales, a meter calibrated on one scale cannot be directly compared with a meter calibrated on the other: accordingly, the findings and conclusions of that study had no validity.

When Folgering et al. [1] designed their subsequent study, they again ignored the principle of comparative stu-dies that "like must be compared with like". They must have been aware of the difference in scales, since they em-phasized that the scale on the mini-Wright meter was equidistant, in contrast to the nonequidistant ATS scale. The Ferraris meter (referred to, incorrectly, as a "Wright pocket meter") must also have been calibrated on the Wright scale, since their figure 1 shows a close similarity between its values and those of the mini-Wright meter.

Ferraris, mini-Wright and Vitalograph meters prescribed in Britain are all calibrated on the Wright scale in order to comply with National Health Service regulations, but each is also available with the ATS scale in countries which prefer it to the Wright scale. The authors would have had no difficulty in obtaining ATS-calibrated miniWright or Ferraris meters in order to achieve uniformity of all the meters under study. Alternatively, they could have converted values measured on the Wright scale to ATS values by means of the charts supplied by manufacturers of meters or by applying the conversion formula of MiLes et al. [4].
Using that formula, it was possible to derive from the values measured by the mini-Wright meter plotted in figure 1 their equivalent ATS values. Had the authors done this, their conclusions about the relative accuracy of the meters would have been very different from their summary in table 8 , in which the mini-Wright meter was shown to be one of the least accurate. In fact, when its values were converted to the ATS scale, it ranked superior to all the others. The same conclusion was made in a much larger study in Japan by ToDA and Makino [5], in which all the meters were calibrated on the ATS scale and hence directly comparable.

A characteristic of peak flow meters which FolGERING et al. [1] indicated as requiring evaluation is their "linearity", though they neither explained this term nor referred to it again. It is important to distinguish it from "equidistance", a word that denotes equality of the spacing between divisions on a calibration scale. Linearity, on the other hand, signifies the correspondence between values measured by a given instrument and those measured by another instrument whose scale is considered to have the closest resemblance to "true" values.

Airflow within the bronchi can only be estimated indirectly. The development of computerized mechanical rigs [6] led to the establishment of the ATS scale of PEF, which many workers believe has a linear relationship to bronchial airflow and therefore reflects it more accurately than the Wright scale. Nevertheless, the latter has served clinical practice well for almost forty years.

The existence of two scales of PEF has already caused much confusion and there is an urgent need to clarify some of the issues. Recognizing how much excellent research in respiratory diseases has been done in the Netherlands, it was disappointing that a mistake in methodology and a failure of peer review to detect it led to a valuable opportunity having been lost.

\section{Gregg}

1 Queens Close, Eynsham, OX8 1HN, UK. Fax: 441865 464234.

\section{References}

1. Folgering $\mathrm{H}$, van de Brink $\mathrm{W}$, Van Heeswijk $\mathrm{O}$, van Herwaarden C. Eleven peak flow meters: a clinical evaluation. Eur Respir J 1998; 11: 188-193.

2. Folgering H, van de Brink W, Van Heeswijk O, van Herwaarden C. Auto-monitoring in obstructive lung disease: a comparison of six peak flow meters. Eur Respir J 1993; 6: Suppl. 17, 286S. (Abstract P0709).

3. Wright BM, McKerrow CB. Maximal forced expiratory flow rate as a measure of ventilatory capacity with a description of a new portable instrument for measuring it. Br Med J 1959; 2: 1041-1047. 
4. Miles JF, Tunnicliffe W, Cayton RM, Ayres JG, Miller MR. Potential effects of corrections of the mini-Wright peak expiratory flow meter on the use of an asthma selfmanagement plan. Thorax 1996; 51: 403-406.

5. Toda M, Makino S. The accuracy of peakflow meters. In: Tsukioka K, ed. Peak Expiratory Flow in Normal Healthy

\section{REPLY}

\section{From the author:}

When monitoring physiological parameters, one can use two types of instruments: monitors and meters. Monitors are instruments that give an impression of changes in physiological parameters and have no pretensions of accurate measurements. Meters are instruments of which one might expect some accuracy and reproducibility. As the manufacturers of the mini-Wright peak flow meter claim that their instrument is a meter, one should be able to expect that the indications that this meter gives, are representative for actual values of airflow. The mini-Wright peak flow meter comes with two scales: the Wright scale, which is equidistant and this was tested in our study, and the so-called American Thoracic Society (ATS) scale, which is nonequidistant.

The scales on both instruments clearly state that they indicate a value of peak flow in $\mathrm{L} \cdot \mathrm{min}^{-1}$. It is somewhat surprising that a manufacturer markets an instrument with two different scales and claims that they are real "meters".

In our study, we did nothing more than compare the values shown by the mini-Wright peak flow "meter" with the values of a calibrated pneumotachograph. We were very well aware of the difference in scales, but we were just as well aware of the fact that both scales suggested that the instrument could measure flows in $\mathrm{L} \cdot \mathrm{min}^{-1}$. The Ferraris meter also had an equidistant scale, and this pocket peak flow meter also claims that it is a "meter" in L.min-1. It would have been more correct to call both instruments peak flow monitors instead of peak flow meters.

We are fully aware of the development of mechanical rigs that can generate a number of patterns of flow volume curves. We never claimed that we did such a kind of calibration and the title of our paper makes that very clear to all readers.

Patients use peak flow meters at home, and also attend hospital for lung function measurements. It would be in the interest of the patients, and of the doctors, to have measurements in which numerical values are comparable, as much as is possible. Any kind of recalculation, either by equations or by scale conversions, would be wasted work.

The elementary mistake in methodology was made by the manufacturers who put two different scales on their instrument, still claiming that both instruments have a readout in $\mathrm{L} \cdot \mathrm{min}^{-1}$, and still calling the instrument a "meter" instead of a monitor.

In their editorial, in this issue, Pedersen et al. again stress the difficulties that can be encountered when evaluating peak flow meters. At the same time they make a number of proposals for standardization of testing procedures.

Pedersen states that a meter scale should not necessarily be linear. Indeed, a number of scales are not linear. However, all scales claim that they show a measurement in
Japanese Subjects. 1995; ISBN 4977211314 (In Japanese with English summary).

6. Hankinson JL, Reynolds JS, Das MK, Viola JO. Method to produce American Thoracic Society flow-time waveforms using a mechanical pump. Eur Respir J 1997; 10: 690-694.

$\mathrm{L} \cdot \mathrm{min}^{-1}$. As the manufacturers make such claims, it can be and ought to be tested against a reference apparatus. This can either be a computer-driven syringe, or a reference flow meter. Irrespective of linear or nonlinear scales, the indication of $\mathrm{L} \cdot \mathrm{min}^{-1}$ should be valid, if the manufacturer makes such claims. The official European Respiratory Society (ERS) statement on peak expiratory flow measurements [1] states that: "the reading from the meter should be linearly related to the flow delivered by the calibration device". This was clearly not the case in several meters in our study, if one accepts a human subject also a flow generating calibration device.

Another potential hazard of nonlinear relationships between real flows and scales on peak flow meters is the possible under-reading in the high zones and the over-reading in the intermediate zones, as occurs with several peak flow meters. This would mean that when the real flow decreases, the peak flow meter will hardly detect the decrease. Thus a deterioration in lung function would go unnoticed for some time with these nonlinear meters.

Pedersen et al. claim that "comparing meters with different scales without correction is misleading". I would submit that putting scales on meters, and claiming to measure flows in $\mathrm{L} \cdot \mathrm{min}^{-1}$, is misleading!

Pedersen concludes in his last paragraph that: "the justification for more publications describing conventional and new peak expiratory flow of spirometric devices in the European Respiratory Journal must be that either some new scientific dimension is added to our knowledge, or special features should be described, for example new principles of measurement or new and special applications: It is my opinion that the justification for more publications describing new peak flow meters should not necessarily be based on such criteria. As soon as new meters are put on the market, they should be tested rigorously and reports of these tests should be made in the literature. As many of these meters are distributed freely by drug companies, the doctors who use these meters should know what the qualities of these meters are.

I fully agree with the editorial that "the ideal would be to obtain a single standard based on true scientific approach, which is satisfactory for both the ATS and the ERS.

\section{H. Folgering}

Dept of Pulmonology, University of Nijmegan, Postbox 9001, NL-6560 GB Groesbeek, The Netherlands. Fax: 31 246859290.

\section{Reference}

1. Quanjer PH, Lebowitz MD, Gregg I, Miller MR, Pedersen OF. Peak expiratory flow: conclusions and recommendations of a working party of the European Respiratory Society. Eur Respir J 1997; 10: Suppl. 24, 25-85. 


\section{Editor's comment}

Having read the above letter from I. Gregg and the reply from $H$. Folgering, I fully support $H$. Folgering in his arguing that this paper is scientifically valid. What he did in his study was to compare the flow values shown on the peak flow meters with the values of a calibrated pneumotachograph. This is appropriate since all the tested meters claimed to measure the flow in $\mathrm{L} \cdot \mathrm{min}^{-1}$. Whether the scale is equidistant, or nonequidistant, is of no relevance in such a comparison. The paper by FolGering et al. [1] underwent our regular peer review process. The responsible Associate Editor and two reviewers, all experts in the field, did not find that the study was flawed in this regard.

The problem is apparent: the old scale, the equidistant Wright scale, does not properly express the peak flow in L.min ${ }^{-1}$, although it claims to do so. O.F. Pedersen, the first author of the editorial in this issue, suggested in a letter to me that a better term for the measured values of the equidistant Wright scale would have been "Wright units". If so, these values would not claim to show the flow in $\mathrm{L} \cdot \mathrm{min}^{-1}$. But as long as meters claim to measure $\mathrm{L} \cdot \mathrm{min}^{-1}$, comparison testing between them is justified, no matter what the scale looks like.

I also received letters from two companies, one from $\mathrm{M}$. Sanders of Clement Clarke International, another from J. Cummings of Ferraris Medical Limited. In these letters, similar arguments as by I. Gregg were put forward. The letters were answered by $\mathrm{H}$. Folgering directly, but space restriction did not allow printing of this lengthy correspondence. The only way to solve the scale problem in the future would be for manufacturers of peak flow meters to agree to a worldwide calibration standard with one accepted scale. As long as this does not exist, a comparison like the one done by FOLGERING et al. [1] is appropriate.

\section{U. Costabel, Chief Editor}

Ruhrlandklinik, Abt. Pneumologie/Allergologie, Tueschener Weg 40, D-45239 Essen, Germany. Fax: 49201433 4029

\section{Reference}

1. Folgering H, Brink Wvd, Heeswijk Ov, Herwaarden Cv. Eleven peak flow meters: a clinical evaluation. Eur Respir J 1998; 11: 188-193. 